\title{
STRATEGI PROMOSI KESEHATAN PUSKESMAS DTP TAROGONG KABUPATEN GARUT
}

\author{
Saleha Rodiah, Evi Rosfiantika dan Andri Yanto \\ Program Studi Ilmu Perpustakaan, Fakultas Ilmu Komunikasi, Universitas Padjadjaran \\ E-mail: saleha_rodiah@yahoo.com
}

\begin{abstract}
ABSTRAK. Penelitian ini bertujuan mengetahui upaya Pusat Kesehatan Masyarakat Dengan Tempat Perawatan (Puskesmas DTP) Tarogong Kabupaten Garut dalam kegiatan strategi promosi kesehatan ditinjau dari : 1) pemberdayaan, 2) bina suasana, 3) advokasi dan 4) kemitraan. Metode penelitian yang digunakan adalah studi kasus, dengan pengumpulan data melalui studi pustaka dan studi lapangan berupa wawancara dan dokumentasi. Dengan teknik purposif, informan penelitian ini berjumlah 9 orang. Kesimpulan penelitiannya adalah: 1) strategi promosi kesehatan melalui pemberdayaan masyarakat dilakukan berjenjang oleh petugas kesehatan Puskesmas DTP Tarogong serta kader pemberdayaan masyarakat (KPM) kepada individu, kelompok dan masyarakat dalam bentuk penyuluhan, konseling, demonstrasi dan dialog; 2) Bina suasana diupayakan melalui kegiatan promosi kesehatan di luar gedung dan di dalam gedung, dengan pengunaan media promosi serta perilaku petugas kesehatan; 3) advokasi ditujukan dan melibatkan komitmen serta dukungan seperti Pimpinan Kecamatan Tarogong Kaler dan Dinas Kesehatan Kabupaten Garut dalam upaya pembuatan kebijakan/ regulasi dan pengadaan sumber daya; dan 4) kemitraan saat ini masih mengandalkan kehadiran mitra yang menawarkan kegiatan tertentu untuk ikut serta dalam kegiatan promosi kesehatan.
\end{abstract}

Kata kunci: Promosi Kesehatan, Strategi Promosi Kesehatan, Pemberdayaan, Bina Suasana, Advokasi

\begin{abstract}
This study aims to determine the effort of a community health center (DTP) Tarogong Garut in the activities of health promotion strategies in terms of: 1) empowerment, 2) social support, 3) advocacy and 4) partnerships. The method used case study approach, the data collection through literature and field studies in the form of interviews and documentation. With purposive technique, informants of this study amounted to 9 people. The results of the research are: 1) the strategy of health promotion through community empowerment carried by health professionals and volunteers from DTP Tarogong empowerment (KPM) to individuals, groups and communities in the form of counseling, counseling, demonstration and dialogue; 2) Social support pursued through health promotion activities outside the building and inside the building, with the use of a media campaign as well as the behavior of health professionals; 3) advocacy directed and involves the commitment and support Camat of Tarogong Kaler and Garut District Health Office in the effort of making the policy / regulation and procurement of resources; and 4) a partnership today still rely on the presence of partners who offer specific activities to participate in health promotion activities.
\end{abstract}

Key words: Health Promotion, Health Promotion Strategy, Empowerement, Social Support, Advocacy

\section{PENDAHULUAN}

Kesehatan mempunyai peran penting bagi kualitas hidup seseorang, sehingga orang selalu berupaya memperoleh informasi kesehatan untuk memenuhi kebutuhan kognitif, afektif dan dapat diterapkan dalam perilaku sehari-hari. Upaya ini ditujukan untuk dapat membantu proses pencegahan penyakit, meningkatkan kualitas kesehatannya serta berperan aktif dalam setiap upaya penyelenggaraan kesehatan.

Kualitas derajat kesehatan masyarakat merupakan salah satu penentu kondisi Indeks Pembangunan Manusia (IPM) yang juga representasi tingkat kesejahteraan masyarakat suatu daerah. Pada tahun 2013, IPM Kabupaten Garut 72.22 poin berada di bawah IPM Jawa Barat 73,11 poin. Hal ini menjadi pemicu Pusat kesehatan masyarakat (puskesmas) dengan tempat perawatan (DTP) Tarogong Kabupaten Garut untuk turut berperanserta aktif meningkatkan IPM Kabupaten Garut, khususnya di bidang kesehatan. Dalam ruang lingkup fasilitas pelayanan masyarakat, upaya ini diwujudkan melalui promosi kesehatan yang mengacu pada Keputusan Menteri Kesehatan Nomor 585/Menkes/SK/V/2007 mengenai Pedoman Pelaksanaan Promosi Kesehatan di Puskesmas.
Data Dinas Kesehatan Garut yang dikutip Ratnasari (2013,3) menggambarkan Kecamatan Tarogong Kaler yang menjadi wilayah kerja Puskesmas DTP Tarogong pada Tahun 2009 sampai dengan 2011 menduduki urutan angka tertinggi ke-4 (empat) yang anggota masyarakatnya menderita deman berdarah dengue (DBD). Hingga Kecamatan Tarogong Kaler menjadi salah satu kecamatan yang endemis DBD di Kabupaten Garut, yaitu kecamatan yang dalam 3 (tiga) tahun terakhir terjangkit DBD setiap tahunnya. Kemudian hasil akreditasi Puskesmas DTP Tarogong belum mendapatkan nilai bagus untuk bidang promosi kesehatan dan kesehatan lingkungan pada layanan enam dasar (the basic six).

Hal tersebut dikuatkan dengan hasil wawancara dengan pengurus Posyandu Strawbery serta Penanggungjawab bidang Kesehatan Lingkungan Puskesmas DTP Tarogong, bahwa masih terdapat warga masyarakat yang buang air besar di sungai, meski telah disediakan jamban umum. Selain itu menurut Koordinator Promosi Kesehatan, Puskesmas Tarogong banyak menerima pasien dengan gangguan sistem pencernaan.

Data tersebut di atas menjadi pijakan bahwa dalam upaya meningkatkan derajat kesehatan masyarakat, masyarakat perlu digugah kesadarannya untuk berperi- 
laku hidup bersih dan sehat (PHBS), sebagaimana tujuan operasional promosi kesehatan di puskesmas. Untuk itu perlu diketahui penerapan strategi promosi kesehatan yang dilakukan oleh Puskesmas DTP Tarogong Kabupaten Garut agar misi yang diembannya dapat tercapai.

Tujuan penelitian ini adalah :

1. Mengetahuibentukpemberdayaanyang diselenggarakan Puskesmas Tarogong

2. Mengetahui upaya bina suasana dalam mempengaruhi individu, keluarga dan masyarakat untuk mencegah penyakit dan meningkatkan kesehatannya

3. Mengetahui kegiatan advokasi agar masyarakat di lingkungan puskesmas berdaya di bidang kesehatan

4. Mengetahui upaya kemitraan yang dikembangkan dalam promosi kesehatan

5.

Pusat Kesehatan Masyarakat (Puskesmas) merupakan penyelenggara upaya kesehatan terdepan. Puskesmas mempunyai 3 fungsi, yaitu 1) sebagai pusat penggerak pembangunan berwawasan kesehatan; 2) Pusat pember-dayaan keluarga dan masyarakat; dan 3) Pusat pelayanan strata pertama.

Saparinah Sadli dalam Notoatmodjo $(2007,150)$ menggambarkan hubungan individu dengan lingkungan sosialnya, yaitu:

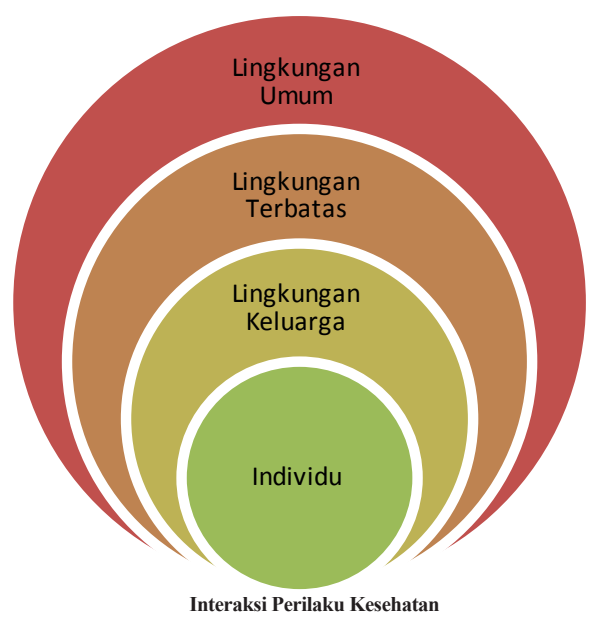

Keterangan :

- Perilaku kesehatan individu: sikap dan kebiasaan individu yang erat kaitannya dengan lingkungan

- Lingkungan keluarga: kebiasaan-kebiasaan tiap anggotakeluarga mengenai kesehatan

- Lingkungan terbatas: tradisi, adat-istiadat dan kepercayaan masyarakat sehubungan dengan kesehatan

- Lingkungan umum: kebijakan-kebijakan pemerintah di bidang kesehatan, undang-undang kesehatan, program-program kesehatan dan sebagainya.

Gambar 1. Hubungan Individu dengan Lingkungan Sosial

Upaya meningkatkan kualitas kesehatan masyarakat tersebut diperlukan strategi agar dapat tercapai secara efektif dan efisien. Surat Keputusan Meteri Kesehatan Nomor 1193/Menkes/SK/X/2004 tentang kebijakan Nasional Promosi Kesehatan dan Surat
Keputusan Menteri Kesehatan Nomor 1114/Menkes/ SK/VII/2005 tentang Pedoman Pelaksanaan Promosi Kesehatan di Daerah, strategi dasar utama Promosi Kesehatan adalah: 1) Pemberdayaan; 2) Bina Suasana, dan 3) advokasi, serta dijiwai semangat 4) kemitraan $(2007,5)$.

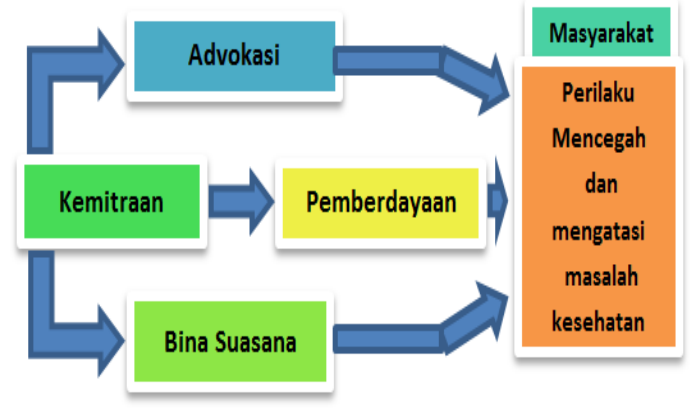

Gambar 2. Strategi Promosi Kesehatan

\section{METODE}

Metode penelitian yang digunakan dalam penelitian ini adalah kualitatif dengan pendekatan studi kasus. Menurut Yin $(2009,1)$, Pendekatan studi kasus merupakan strategi yang cocok bila pokok pertanyaan suatu penelitian berkenaan dengan bagaimana dan mengapa, bila peneliti memiliki sedikit peluang untuk mengontrol peristiwa-peristiwa yang akan diselidiki dan fokus penelitiannya terletak pada fenomena kontemporer (masa kini) di dalam kehidupan nyata.

Informan dipilih secara purposif berdasarkan keterkaitannya dengan strategi promosi kesehatan di Puskesmas DTP Tarogong Kabupaten Garut. Informan antara lain terdiri dari : Koordinator Promosi Kesehatan Puskesmas DTP Tarogong, Kepala Seksi Promosi Kesehatan Dinas Kesehatan Kabupaten Garut, penanggungjawab Promosi Kesehatan bidang Kesehatan Ibu dan Anak, Kasubbag Perencanaan Evaluasi dan Pelaporan Kec. Tarogong Kaler yang aktif dalam kegiatan PKK tingkat kecamatan, Pengelola Posyandu Strawberry RW 11 Desa Pasawahan Kecamatan Tarogong Kaler serta Enung dan Herman, masyarakat pengguna layanan Puskesmas DTP Tarogong.

\section{HASIL DAN PEMBAHASAN}

Upaya peningkatan kesehatan melalui perilaku hidup bersih dan sehat (PHBS) merupakan tujuan kegiatan promosi kesehatan. PHBS juga bermanfaat untuk meningkatkan citra pemerintah daerah, sehingga menjadi contoh rumah tangga sehat bagi daerah lain.

Perilaku sehat yang menjadi bagian dari 10 PHBS tatanan keluarga adalah : 1) Persalinan ditolong oleh tenaga kesehatan; 2) Memberi ASI Ekslusif; 3) Menimbang balita setiap bulan; 4) Menggunakan air bersih; 5) Mencuci tangan dengan air bersih dan sabun; 6) Menggunakan jamban sehat; dan 7) Memberantas jentik di rumah sekali seminggu. Sedangkan 3 (tiga) gaya hidup yang termasuk dalam PHBS rumah tangga, 
yaitu : 1) Makan buah dan sayur; 2) Melakukan aktifitas fisik setiap hari; dan 3) tidak merokok di dalam rumah

\section{Pemberdayaan Masyarakat}

Masyarakat sebagai sasaran primer (primary target) promosi kesehatan diberdayakan agar mereka mau dan mampu memelihara kesehatannya. Pemberdayaan individu umumnya dilakukan oleh petugas kesehatan puskesmas terhadap individu-individu yang datang memanfaatkan pelayanan puskesmas. Dapat juga individuindividu yang menjadi sasaran kunjungan, misalnya upaya keperawatan kesehatan masyarakat.

Pemberdayaan melalui kegiatan konseling interpersonal (KIPKA) dilakukan tergantung permintaan pengunjung puskesmas ataupun bila terdeteksi perlu penanganan khusus, sebagaimana dipaparkan oleh Informan sebagai berikut:

Kita ada konseling interpersonal, dari BP Umum rujukannya, ketika pemeriksaan terdeteksi, ada kekurangan dari sehat yang ideal itu nanti dirujukkan ke kami/kita. Ke luar gedung. Misalnya, bayi dari penimbangan artotemiti harus usia sekian kurang misalnya. Coba ibu konsultasikan ke belakang. temui ke bagian gizi.

Di sini orang tua dan petugas promosi kesehatan akanberbincang-bincang mengenai cara penanganannya, antara lain dengan memberikan pengaturan pola makan. Dalam perbincangan dengan orangtua pasien, dilakukan upaya peningkatan pengetahuannya, misalnya dengan penggunaan alat peraga food modelling, pengetahuan cara mencuci dan memasak sayuran.

Pemberdayaan terhadap masyarakat (sekelompok anggota masyarakat) yang dilakukan oleh petugas puskesmas merupakan upaya penggerakkan atau pengorganisasian masyarakat. Karena keterbatasan sumber daya manusia di Puskesmas DTP Tarogong dalam pemberdayaan individu ini, terdapat kader-kader desa atau kader pemberdaya masyarakat (KPM), yaitu para sukarelawan yang mempunyai kepedulian terhadap peningkatan kualitas kesehatan lingkungan sekitarnya.

Di Puskesmas Tarogong terdeteksi banyak pasien yang mengalami gangguan pencernaan, maka untuk mengatasinya dilakukan metode demostrasi mencuci tangan dengan sabun untuk meningkatkan hidup sehat uraian mengenai hal ini diungkapkan Informan sebagai berikut:

Demonstrasi biasanya itu dilakukan dalam gedung dan luar gedung. Demonstrasi di dalam gedung misal di ruang perawatan, bagaimana cuci tangan menggunakan sabun, kan kita demonstrasi.

Proses pemberdayaan yang dilakukan Puskesmas DTP Tarogong dapat digambarkan sebagaimana adaptasi proses pemberdayaan Notoatmodjo $(2007,110)$ berikut ini Kegiatan pemberdayaan yang dilakukan Puskesmas DTP Tarogong untuk mempercepat peningkatan derajat kualitas kesehatan masyarakat dilakukan dengan penyampaian informasi kesehatan, agar masyarakat mempunyai kesadaran tentang kesehatan pribadi, keluarga dan lingkungannya. Dengan pengetahuan kesehatan diharapkan adanya kemauan berperilaku hidup sehat (PHBS), sehingga dapat disebut sebagai berdaya dalam kesehatan.

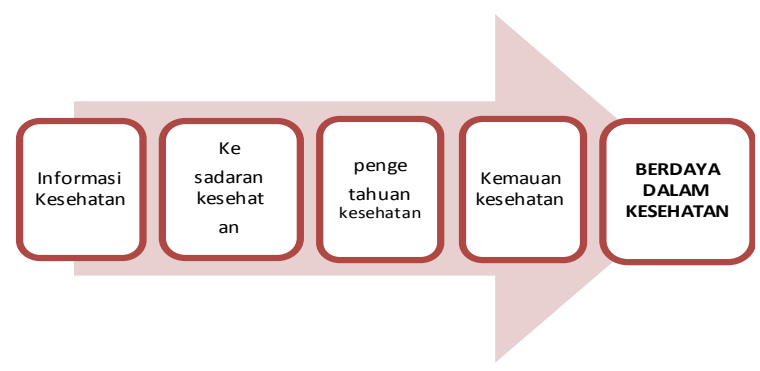

Gambar 3. Proses Pemberdayaan

Sebagaimana tahapan dalam pemberdayaan menurut Mardikanto dan Soebiato $(2012,123)$ antara lain berupaya Membantu pemecahan masalah, sejak analisis akar-masalah, analisis alternative pemecahan masalah, serta pilihan alternatif pemecahan terbaik yang dapat dilakukan sesuai dengan kondisi internal (kekuatan kelemahan) maupun kondisi eksternal (peluang dan ancaman) yang dihadapi; serta menunjukkan pentingnya perubahan, yang sedang dan akan terjadi di lingkungannya, baik lingkungan organisasi dan masyarakat (lokal, nasional, regional dan global). Karena kondisi lingkungan (internal dan eksternal) terus mengalami perubahan yang semakin cepat, maka masyarakat juga harus disiapkan untuk mengantisipasi perubahan tersebut melalui kegiatan "perubahan yang terencana".

\section{Bina Suasana}

Strategi promosi melalui pemberdayaan akan lebih cepat berhasil apabila didukung dengan upaya menciptakan suasana atau lingkungan yang kondusif. Menciptakan lingkungan yang sehat di dalam dan di luar gedung puskesmas menjadi salah satu tujuan yang ingin dicapai. Lingkungan yang sehat akan mendorong masyarakat berperilaku hidup sehat lihat Liliwei, 2010.

Informasi-informasi yang disampaikan melalui media informasi dapat dijadikan petunjuk bagi pengunjung puskesmas bahwa mereka berada dalam lingkungan yang mendukung upaya peningkatan kualitas kesehatan. Informasi tersebut dipampang di tempat pendaftaran, apotek, Instalasi Gawat Darurat (IGD), tempat parkir dan ruang-ruang lainnya di puskesmas.

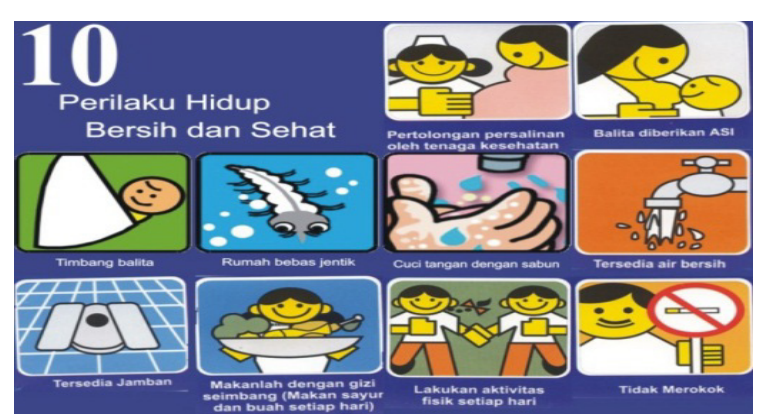

Gambar 4. Contoh Poster PHBS 
Puskesmas DTP Tarogong juga melakukan bina suasana dalam gedung dengan media audiovisual, pemutaran film tentang kesehatan di ruang tunggu Balai Pengobatan Umum yang ditayangkan pada waktu ramai pengunjung, yaitu antara pukul 09.00 sampai 12.00.

Terdapat upaya bina suasana berkaitan dengan jajanan sehat di lingkungan Puskesmas DTP Tarogong yang menjadikan masyarakat tidak khawatir saat mengkonsumsi jajanan di lingkungan kantin Puskesmas dengan pembinaan dari petugas promosi kesehatan bidang gizi. dilihat di Hartono, B. (2010).

Setiap yang jualan di sini, sudah kita cek dan sampelnya diambil. Hal tersebut dilakukan oleh dinas kesehatan. Seperti pelatihan mengenai jajanan sehat, lalu gerobak tersebut akan diberikan label bahwa telah diberikan pelatihan jajanan sehat.

\section{Kegiatan Advokasi}

Petugas promosi kesehatan yang berada di puskesmas sebagai ujung tombak dalam pelaksanaan promosi kesehatan di level kecamatan. Fungsional promosi kesehatan inilah yang diharapkan dapat meningkatkan kesadaran masyarakat untuk berperilaku hidup bersih dan sehat (PHBS). Promosi kesehatan yang diaplikasikan ke dalam kegiatan Posyandu diharapkan muncul DKSA (Desa Kelurahan Siaga Aktif).

Advokasi juga dilakukan dengan menggunakan pendekatan terhadap orang-orang yang dianggap mempunyai pengaruh di lingkungan atau wilayahnya. Metode dan teknik advokasi yang dilakukan petugas promosi kesehatan mulai dari lobi-lobi politik dengan cara berbincang secara nonformal dengan para pejabat pemerintahan untuk menginformasikan dan membahas program PHBS, agar diperoleh dukungan atau komitmen dari pembuat keputusan dengan mengeluarkan peraturan yang berkaitan dengan kegiatan PHBS. Dukungan ini juga dapat diperoleh dari pihak yang ada di luar pemerintahan, seperti produsen obat-obatan.

Advokasi lainnya yang dilakukan oleh UPTD Puskesmas Kecamatan Tarogong seperti yang telah dilakukan oleh informan dalam kegiatan advokasi misalnya:

"di level tingkat puskesmas kita bekerja sama dengan Surveilans. Ada program surveilans untuk penanggulangan penyakit, seperti DBD, dan lain sebagainya. Kita kerjasama langsung, nah seperti apa teknisnya, sama-sama ke lapangan untuk menyampaikan seperti kalau penyakit di sini seperti DBD, Cikungunya. Jadi advokasinya kita menyampaikan penyuluhan, berupa penyuluhan kepada masyarakat itu bagaimana mengantisipasi penyakit-penyakit tersebut.

Jadi bentuk advokasi yang dilakukan selain dengan pendekatan melalui orang-orang yang membuat kebijakan dan lain sebagainya serta dengan berbagai tokoh masyarakat ataupun pihak swasta dan organisasi kemasyarakatan lainnya.
Ditinjau dari ilmu komunikasi, advokasi sebagai salah satu komunikasi interpersonal maupun massa yang dtujukan pada para penentu kebijakan (policy makers) atau para pembuat keputusan (decision makers) pada semua tingkatan social. Secara inklusif, advokasi bertujuan sebagai political commitment, policy support, social acceptance and system support. (Notoatmodjo, 2007, 1 .

Selain itu petugas promosi kesehatan juga meng-gunakan media dalam bentuk seminar, presentasi/ penyuluhan yang dihadiri oleh pejabat dari berbagai lintas sektor serta menggunakan media massa, misalnya memasukkan profil bidan desa Puskesmas TP Tarogong ke Majalah Kesehatan. Salah satu kegiatan advokasi lainnya adalah terbentuknya pokjanal (kelompok kerja nasional) berkaitan dengan gebyar PHBS. Kecamatan Tarogong dapat digambarkan sebagai berikut:

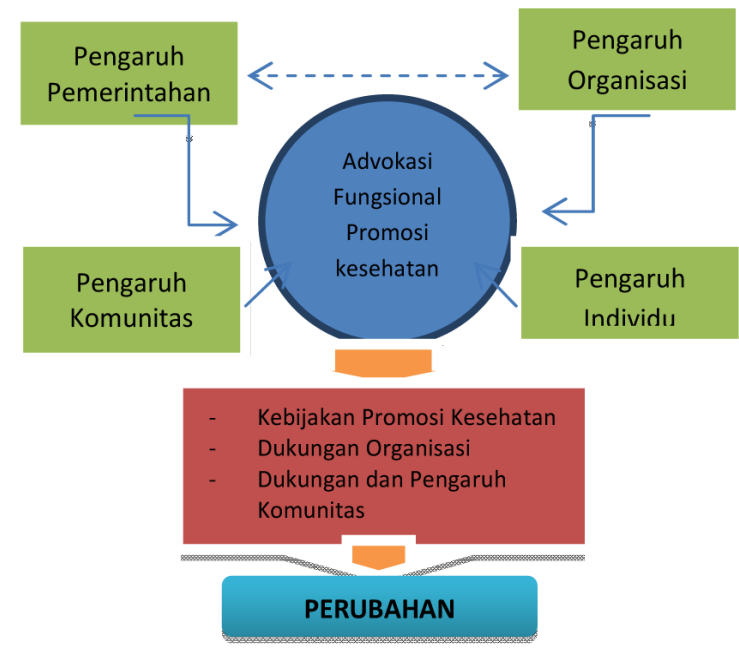

Gambar 5. Model Advokasi Fungsional Promosi Kesehatan

Penjelasan Gambar 5 mengenai "Model Advokasi Fungsional Promosi Kesehatan", Pengaruh Pemerintah (Influence Government) dan Pengaruh Organisasi (Influence Organization) menjadi pedoman utama (guidance) para petugas promosi kesehatan dalam menjalankan tugas utama promosi kesehatan berdasarkan kebijakan atau peraturan yang dikeluarkan pemerintah.

Kemudian Pengaruh Komunitas (Influence Community) dan Pengaruh Individu (Influence Individual) menjadi pendukung utama operasionalisasi kegiatan promosi kesehatan di masyarakat. Keempat pilar ini menjadi faktor yang menentukan kesuksesan para tenaga fungsional promosi kesehatan dalam memberikan pendampingan serta memberikan aksesibilitas informasi kesehatan masyarakat.

\section{Kemitraan}

Petugas promosi kesehatan Puskesmas DTP Tarogong dengan sasarannya (para pasien atau pihak lain) dalam pelaksanaan pemberdayaan, bina suasana dan advokasi berupaya menjalin kemitraan dengan berbagai pihak. 
Menurut Informan bahwa kemitraan hanya dilakukan dengan instansi pemerintah lainnya ( $G$ to G) dalam bentuk lintas sektor, hal ini dapat dilihat dari pernyataan informan bahwa : "Jarang ada kemitraan, kalo ada media promosi, itu droping pemerintah, seperti alat kontrasepsi gratis. IUD gratis.... kerjasama lintas sektor, dengan BKKBN."

Namun terdapat kerjasama yang dilakukan dengan asosiasi profesi ataupun dengan lembaga non peme-rintahan lainnya. Sehingga dapat disebutkan bahwa kemitraan yang dibangun saat ini hanya mengandalkan penawaran dari lembaga lain, tanpa adanya inisiatif dari fungsional promosi kesehatan yang ada di Puskesmas.

Kemitraan dengan media cetak sejak 2011, memberikan konsultasi kesehatan keluarga melalui majalah tingkat kabupaten garut

Kemitraan masih sangat minim dilakukan karena fungsional promosi kesehatan masih fokus pada program-program rutin yang ada di puskesmas ataupun melaksanakan kebijakan tingkat atas dan relatif masih baru menjabat fungsional promosi kesehatan. Diharapkan ke depan petugas promosi kesehatan dapat bersinergi bersinergi untuk mencapai tujuan bersama menciptakan masyarakat yang berperilaku hidup bersih dan sehat.

Dari penelitian ini diperoleh strategi menjalin kemitraan yang dikembangkan Puskesmas DTP Tarogong dalam meningkatkan efektivitas promosi kesehatan dengan tetap memegang prinsip dasar kemitraan.

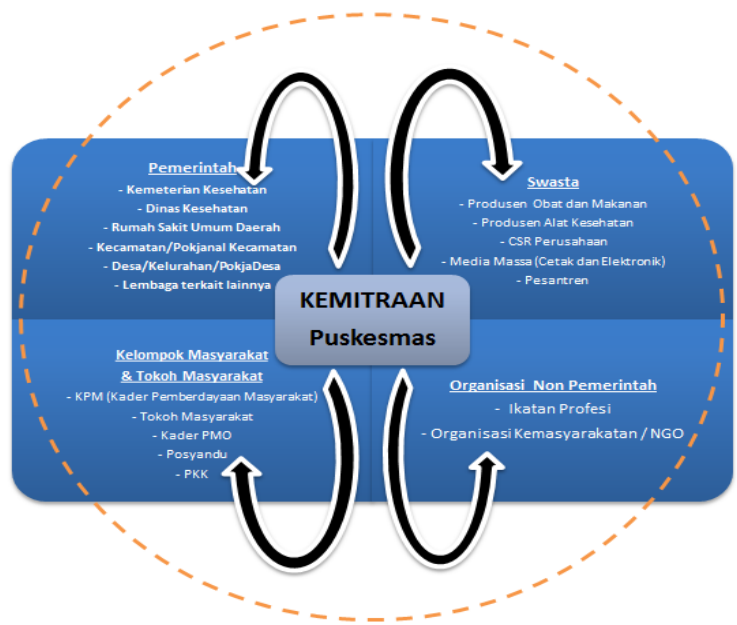

Gambar 6. Model Kemitraan Oleh Fungsional Promosi Kesehatan

Dari hasil penelitian dapat digambarkan model strategi promosi kesehatan Puskesmas DTP Tarogong Kabupaten Garut, yang ditinjau dari Pemberdayaan, bina suasana, advokasi dan kemitraan sebagai berikut:

Kegiatan promosi kesehatan yang telah dilakukan di puskesmas Tarogong bertumpu pada program yang telah dirancang oleh petugas kesehatan yang bersumber pada kebijakan pemerintah. Program dijalankan sesuai dengan kemampuan dan kreativitas petugas masingmasing, secara keseluruhan kegiatan promosi kesehatan sudah berjalan sesuai dengan tahapan strategi promosi kesehatan yang dicanangkan oleh pemerintah

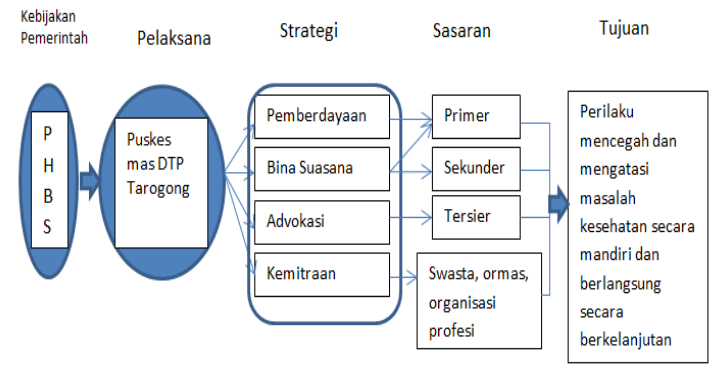

Gambar 7. Model Strategi Promosi Kesehatan Puskesmas DTP Tarogong

Partisipasi dan kesempatan masyarakat untuk terlibat dalam keseluruhan proses perencanaan dan pelaksanaan belum tercapai secara optimal. Program yang bisa menyelesaikan dan memenuhi kebutuhan masyarakat adalah program yang disusun sendiri oleh masyarakat. Kegiatan promosi kesehatan bukan sekedar kewajiban yang harus dilakukan oleh petugas pemerintah sendiri tetapi juga menuntut keterlibatan masyarakat yang secara langsung akan diperbaiki dan ditingkatkan kualitas derajat kesehatannya.

Untuk itu, dibutuhkan program yang bisa menampung aspirasi masyarakat bukan sekedar program untuk menjalankan program pemerintah seperti yang terjadi saat ini, yaitu strategi promosi kesehatan dilakukan untuk merealisasikan program pemerintah tanpa ada keterlibatan partisipasi masyarakat secara luas. Partisipasi masyarakat secara luas dibutuhkan agar sasaran PHBS dapat terealisasikan dengan cepat dan masif.

Program bina suasana di puskesmas Tarogong saat ini baru menciptakan iklim dan suasana fisik misalnya dengan pemutaran film kesehatan, pemasanganpemasangan poster, spanduk dan lain-lain. Dalam hal ini diperlukan langkah-langkah lebih positif yang dapat membangkitkan kesadaran dan pemahaman masyarakat melalui program-program khusus yang terintegrasi dengan kegiatan masyarakat sekitar puskesmas. Sebagaimana tujuan desa siaga yang telah digebyarkan, dengan adanya percontohan upaya PHBS, terutama dengan warga di sekitar puskesmas.

Seringkali pemerintah mengukur keberhasilan program setelah dilaksanakan sesuai dengan yang telah direncanakan padahal masyarakat belum bisa memanfaatkan hasilnya atau pembangunan yang dilakukan hanya berdasarkan keinginan proyek pemerintah semata, belum didasarkan pada kebutuhan dan pemintaan masyarakat.

\section{SIMPULAN}

Pemberdayaan masyarakat oleh Puskesmas DTP Tarogong berjenjang, mulai dari individu, kelompok dan masyarakat dengan upaya pembentukkan perilaku hidup bersih, sehat (PHBS); Bina suasana diupayakan melalui pengunaan media promosi poster, spanduk dan televisi yang ditempatkan di halaman, balai pengobatan umum, dan dinding puskesmas serta penciptaan lingkungan 
yang mendukung, seperti perilaku kesehatan petugas kesehatan, kantin sehat dan lingkungan yang bebas asap rokok: Advokasi melibatkan komitmen dan dukungan Pimpinan Kecamatan Tarogong Kaler dan Dinas Kesehatan Kabupaten Garut dalam upaya pembuatan kebijakan/ regulasi dan pengadaan sumber daya dalam upaya mencegah penyakit dan menciptakan lingkungan sehat; Saat ini masih mengandalkan penawaran mitra untuk ikut serta dalam kegiatan promosi kesehatan atau perpanjangan kemitraan yang sudah dibangun oleh Dinas Kesehatan Kabupaten Garut. Kemitraan yang sudah dilakukan Puskesmas DTP Tarogong antara lain dengan majalah kesehatan dan organisasi profesi (PDGI)

\section{DAFTAR PUSTAKA}

Depkes RI, 2005. Surat Keputusan Menteri Kesehatan Nomor 1114/Menkes/SK/VII/2005 tentang Pedoman Pelaksanaan Promosi Kesehatan Daerah

Departemen Kesehatan RI, 2004. Keputusan Menteri Kesehatan RI No. 1193/MENKES/SK/2004 tentang Kebijakan Dasar Pusat Kesehatan Masyarakat

Dinas Kesehatan Garut, 2011. Surat Keputusan Kepala Puskesmas DTP Tarogong No. 440// PKM/2011 tentang Pedoman Pelaksanaan Promosi Kesehatan di Puskesmas Garut Dinas Kesehatan Kabupaten Garut
Hartono, B. 2010. Promosi Kesehatan di Puskesmas dan Rumah Sakit. Jakarta : Rineka Cipta

Liliweri, A. 2011. Dasar-dasar Komunikasi Kesehatan. Yogyakarta : Pustaka Pelajar

Mardikanto, Totok dan Poerwoko Soebiato. 2012. Pemberdayaan Masyarakat Dalam Perspektif Kebijakan Publik. Bandung : Alfabeta.

Nasrul, K.L. dan Herman, S. 2010. Intervension of Standard and Persuasive Messages in Health Promotion Education Toward Practices of Pregnant Women in The District of Buol. Buletin Penelitian Kesehatan. Vol.13, No.3 Juli (2010). http://ejournal.litbang.depkes. go.id/index.php/hsr/article/view/2262

Notoatmodjo, S. 2007. Promosi Kesehatan dan Ilmu Perilaku. Jakarta : Rineka Cipta

Ratnasari, D. 2013. Persebaran Penderita DBD di Kecamatan Tarogong Kidul Kabupaten Garut. Bandung: Universitas Pendidikan Indonesia http://repository.upi.edu/5034/8/S_ GEO_0907128_pdf

Yin, 2008. Studi Kasus: Desain dan Metode, cet. 8. Jakarta: Raja Grafindo Persada 